\title{
Concordance of interim and final estimates of influenza vaccine effectiveness: a systematic review
}

VK Leung ${ }^{1}$, BJ Cowling ${ }^{2}$, S Feng 2 , SG Sullivan ${ }^{13}$

1. World Health Organization Collaborating Centre for Reference and Research on Influenza, Peter Doherty Institute for Infection and Immunity, Melbourne, Australia

2. World Health Organization Collaborating Centre for Infectious Disease Epidemiology and Control, School of Public Health, Li Ka Shing Faculty of Medicine, The University of Hong Kong, Hong Kong Special Administrative Region, China

3. Fielding School of Public Health, University of California, Los Angeles, United States

Correspondence: Sheena Sullivan (sheena.sullivan@influenzacentre.org)

Citation style for this article:

Leung VK, Cowling BJ, Feng S, Sullivan SG. Concordance of interim and final estimates of influenza vaccine effectiveness: a systematic review. Euro Surveill. 2016;21(16):pii=30202. DOI: http://dx.doi.org/10.2807/1560-7917.ES.2016.21.16.30202

The World Health Organization's Global Influenza Surveillance and Response System meets twice a year to generate a recommendation for the composition of the seasonal influenza vaccine. Interim vaccine effectiveness (VE) estimates provide a preliminary indication of influenza vaccine performance during the season and may be useful for decision making. We reviewed 17 pairs of studies reporting 33 pairs of interim and final estimates using the test-negative design to evaluate whether interim estimates can reliably predict final estimates. We examined features of the study design that may be correlated with interim estimates being substantially different from their final estimates and identified differences related to change in study period and concomitant changes in sample size, proportion vaccinated and proportion of cases. An absolute difference of no more than $10 \%$ between interim and final estimates was found for 18 of 33 reported pairs of estimates, including six of 12 pairs reporting VE against any influenza, six of 10 for influenza $A\left(\mathrm{H}_{1} \mathrm{~N}_{1}\right)$ pdmo9, four of seven for influenza $A\left(\mathrm{H}_{3} \mathrm{~N}_{2}\right)$ and two of four for influenza $B$. While we identified inconsistencies in the methods, the similarities between interim and final estimates support the utility of generating and disseminating preliminary estimates of VE while virus circulation is ongoing.

\section{Introduction}

Influenza vaccination is currently the main strategy for reducing the burden of influenza morbidity and mortality. Influenza viruses continuously evolve by undergoing antigenic drift and the composition of influenza vaccines therefore varies each year to account for antigenic changes in circulating viruses. The inability to use randomised trials to measure the efficacy of the influenza vaccine each year has resulted in the use of observational studies to determine annual vaccine effectiveness. However, observational studies such as cohort or case control studies can be subject to a number of biases.

The test-negative design (TND) is increasingly being used to measure influenza vaccine effectiveness (VE). The theory and methodology behind the TND has been discussed in detail previously [1-3]. Briefly, patients presenting for medical attention with a respiratory infection are swabbed and tested for influenza. Those testing positive are the cases and those testing negative are the comparison group [3]. Laboratory end points such as PCR-confirmed influenza are preferred in the TND, rather than low-specificity endpoints which could lead to underestimation of the effect of vaccination [4].

This design is favoured for the reporting of mid-season estimates, which provide a preliminary indication of vaccine performance during the season [5-21]. Early VE estimates may be useful to public health authorities in the event of a pandemic or in a season where VE appears to be low, to guide resource allocation or initiate additional preventive measures. Belongia et al. have shown that interim estimates can be reliable to within 10 percentage points of the final estimate [22], while Sullivan et al. demonstrated that estimates made in seasons with an early start showed greatest reliability to within 10 percentage points [19]. JimenezJorge et al. also found agreement between mid- and end-of-season estimates in their comparison over four seasons in Spain [23], supporting the use of interim estimates. However, studies of interim influenza VE estimates might be expected to ignore desired exclusion criteria due to small sample sizes and incomplete data. The objective of this review is to examine differences in reported interim and final influenza vaccine effectiveness estimates derived by the test-negative design, with particular reference to changes in the 
analytical approach used between interim and final estimation.

\section{Methods}

\section{Search strategy}

Studies reporting influenza VE estimates were initially retrieved from PubMed on 8 November 2013 as part of a review of test-negative studies which focused solely on final estimates, excluding interim estimates [24]. At that time, articles were searched using combinations of the following terms: (i) 'influenza' OR 'flu', (ii) 'vaccine effectiveness OR 'VE', (iii) 'test-negative' OR 'test negative' OR 'case-control' OR 'case control'.

We used the list of excluded papers to identify interim estimates for this review. In addition, a further search of PubMed, Medline, Web of Science and Embase was conducted on 19 December 2014 and updated on 5 December 2015 using the above search terms as well as the following: (iv) 'interim' OR 'mid-season' OR 'mid season' OR 'early estimates'.

Complementary to the online search, the reference lists of retrieved articles were reviewed to identify additional studies. Articles were also identified, between May 2012 and December 2015, from influenza email alerts from the Centre for Infectious Disease Research and Policy (CIDRAP, http://www.cidrap.umn.edu/). We excluded articles which did not use the test-negative design or were a re-analysis of data, end of season analyses without corresponding interim analyses and interim analyses without corresponding final analyses. Searches were limited to articles in English only.

The titles of all papers identified were independently screened by two authors (VKL and SGS). Abstracts of potentially relevant papers were reviewed for eligibility, and the full text of eligible articles was reviewed. Studies reporting interim effectiveness estimates for any type of influenza vaccine (trivalent inactivated, live-attenuated, monovalent, adjuvanted/non-adjuvanted or unspecified) were considered.

Once all interim papers were identified, their corresponding end-of-season report was located. This was a specific search using the author names, location and season of the interim paper to identify the paper reporting final estimates.

\section{Data retrieval}

Study design and analysis features were reviewed for each article using a standardised data collection form. Specific features reviewed included the study setting, source population, case definition (including whether acute respiratory illness or influenza-like illness was used and any restrictions on time since symptom onset) exposure definition (including any restrictions on the period between vaccination and symptoms onset), study period or season, timing of interim estimates in relation to the peak (determined by reviewing
FIGURE 1

PRISMA flow diagram showing search strategy

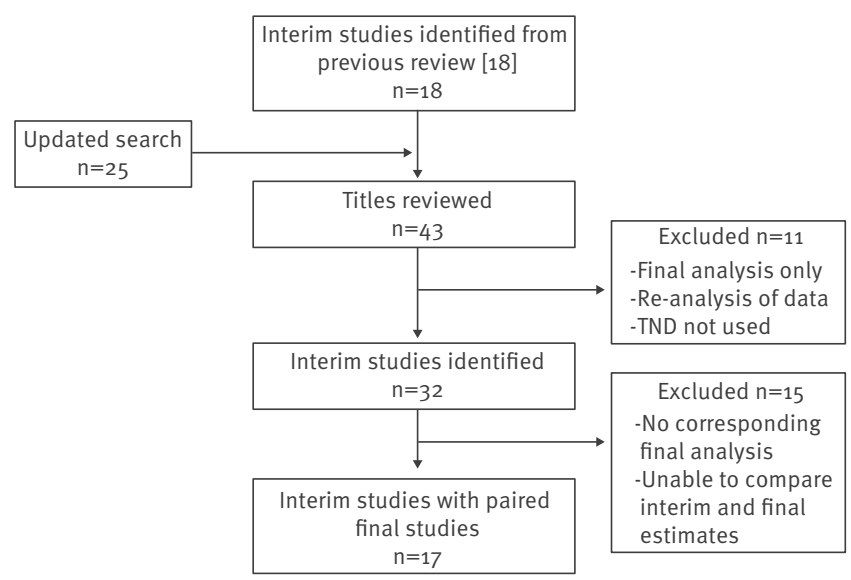

PRISMA: preferred reporting items for systematic reviews and meta-analyses; TND: test-negative design.

the epidemic curve provided in final analyses), any other exclusions (e.g. patients with missing information, children younger than a certain age), variables included in the model to estimate VE and their specification, and reported interim and final VE estimates. If the methods referred to a previous paper, the methods in the previous paper were recorded. If the specification of a variable was not mentioned, it was assumed that it had not been taken into consideration in the analysis. In some instances where information was not available, the authors were contacted to provide this information.

\section{Comparison of interim and final estimates}

The VE estimates reported by each interim/final study pair were plotted using forest plots and compared visually. Changes between interim and final estimates of 10 or more percentage points were considered meaningful differences $[19,22]$. The difference in VE estimates $(\triangle \mathrm{VE})$ between final and interim analyses was calculated. Confidence intervals were estimated using bootstrapping and were based on each study's standard error estimated from reported confidence intervals. We attempted to evaluate whether any design features were associated with $\triangle V E$. This was done in two ways: (i) univariate linear regression, modelling each design feature explored on the absolute value of $\triangle \mathrm{VE}$, and (ii) logistic regression, where the outcome was a change in $\triangle V E$ of 10 or more percentage points. Multivariate models were explored using stepwise regression to identify which variables were most influential on the value of $\triangle V E$ or a change in $\triangle V E$ of 10 or more percentage points. We used stepwise regression to limit the size of the final model; given the small number of data points, a full model would have been overparameterised. Akaike information criterion (AIC) were used to choose variables for the final model using the stepAIC package in R. Design features were specified as the absolute difference between interim and final estimate 


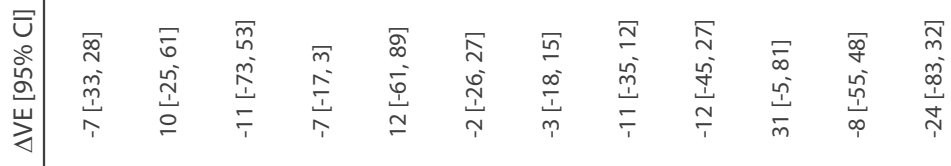

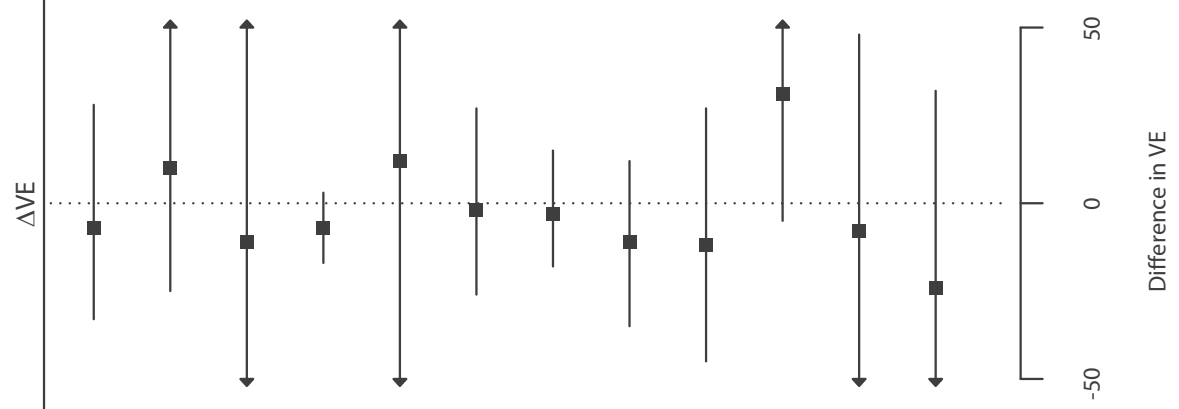

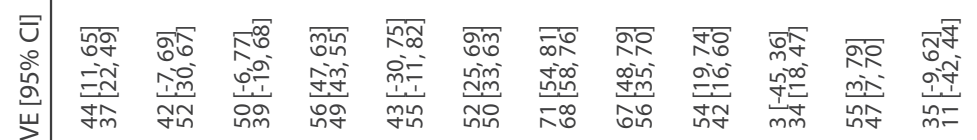

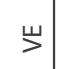

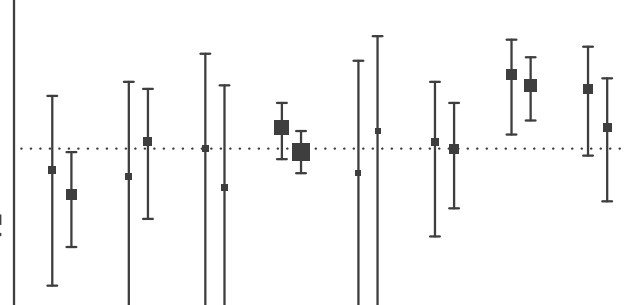

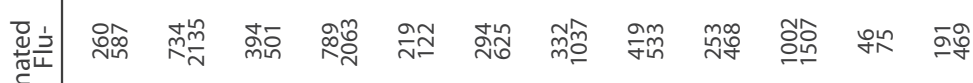

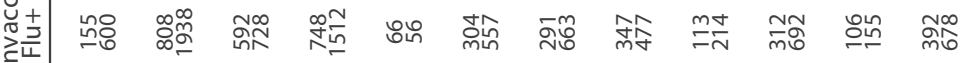

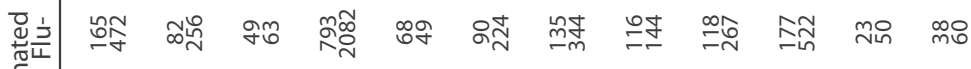

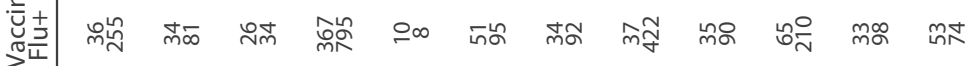

ᄃ요

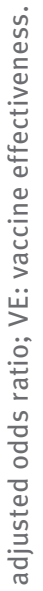

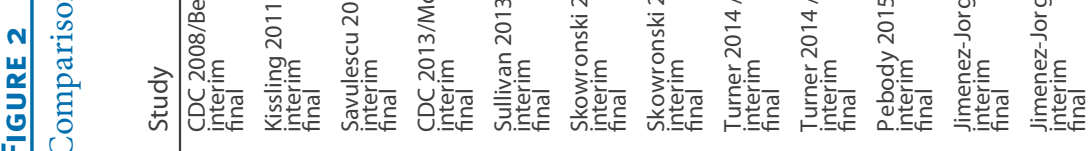




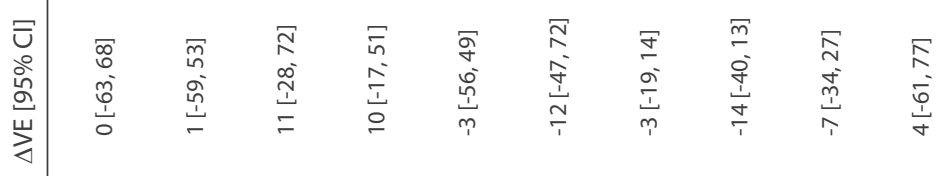

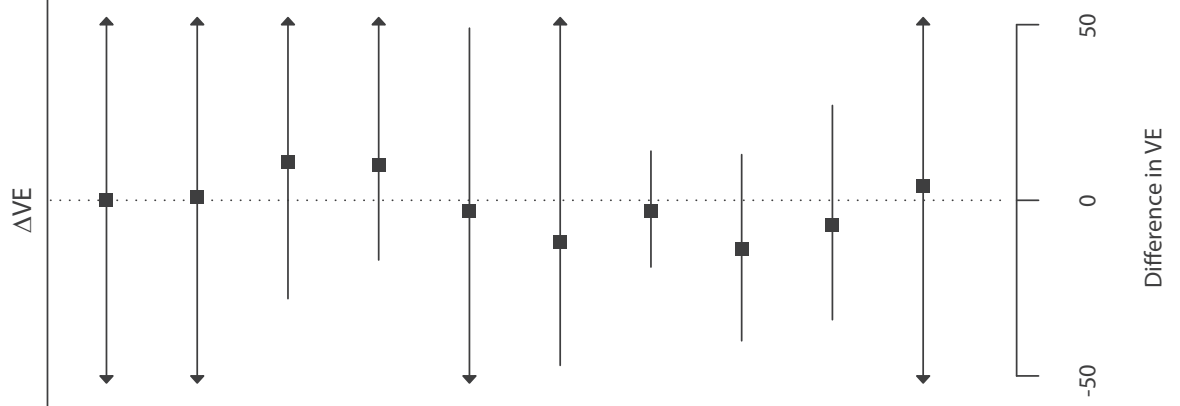

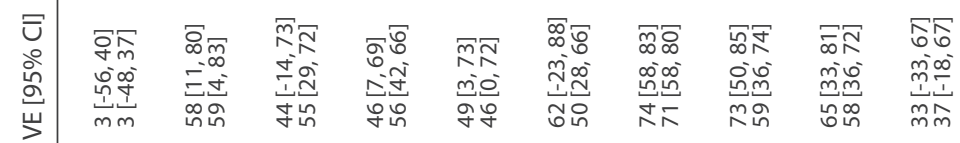

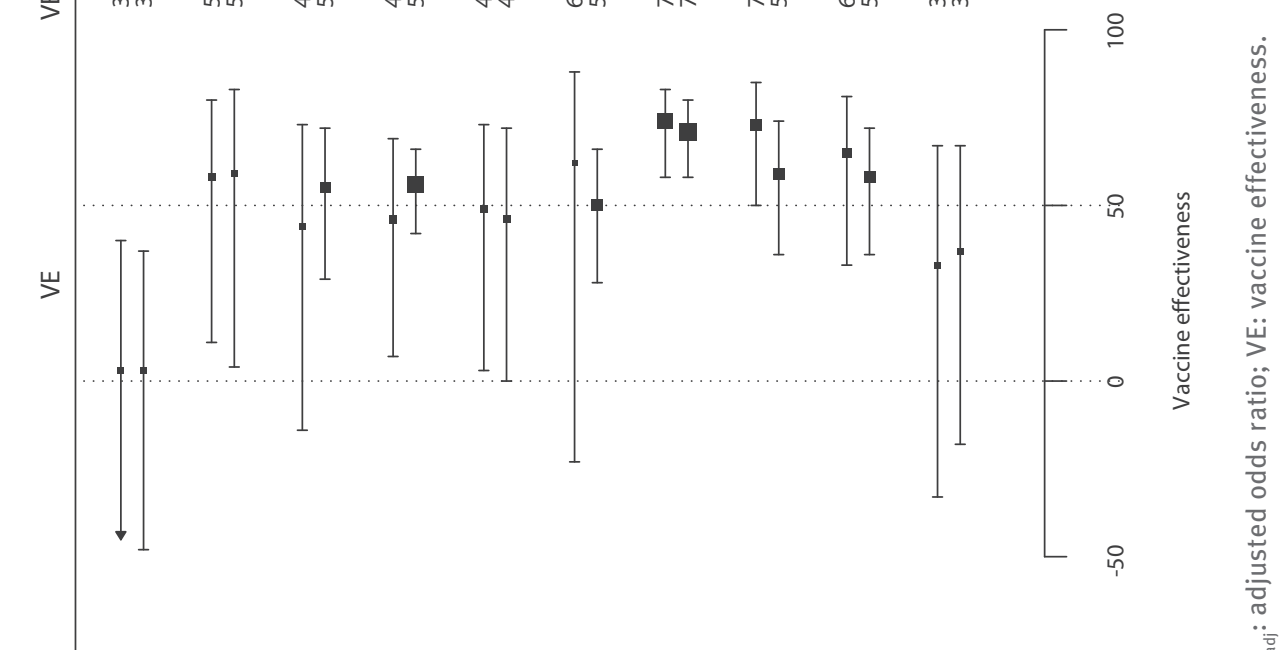

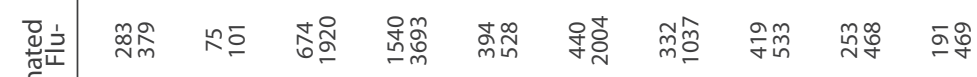

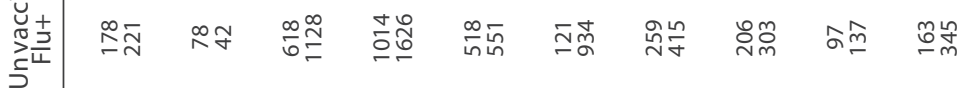

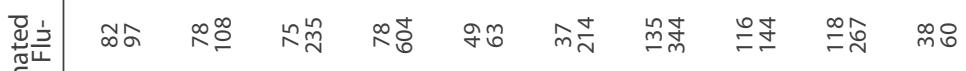

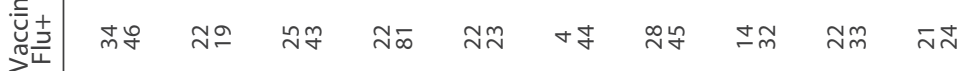

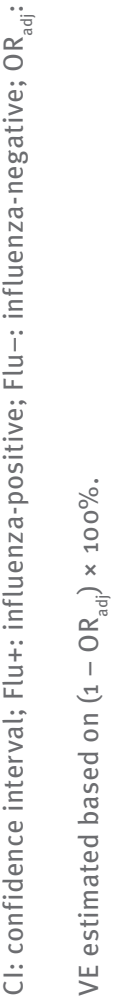




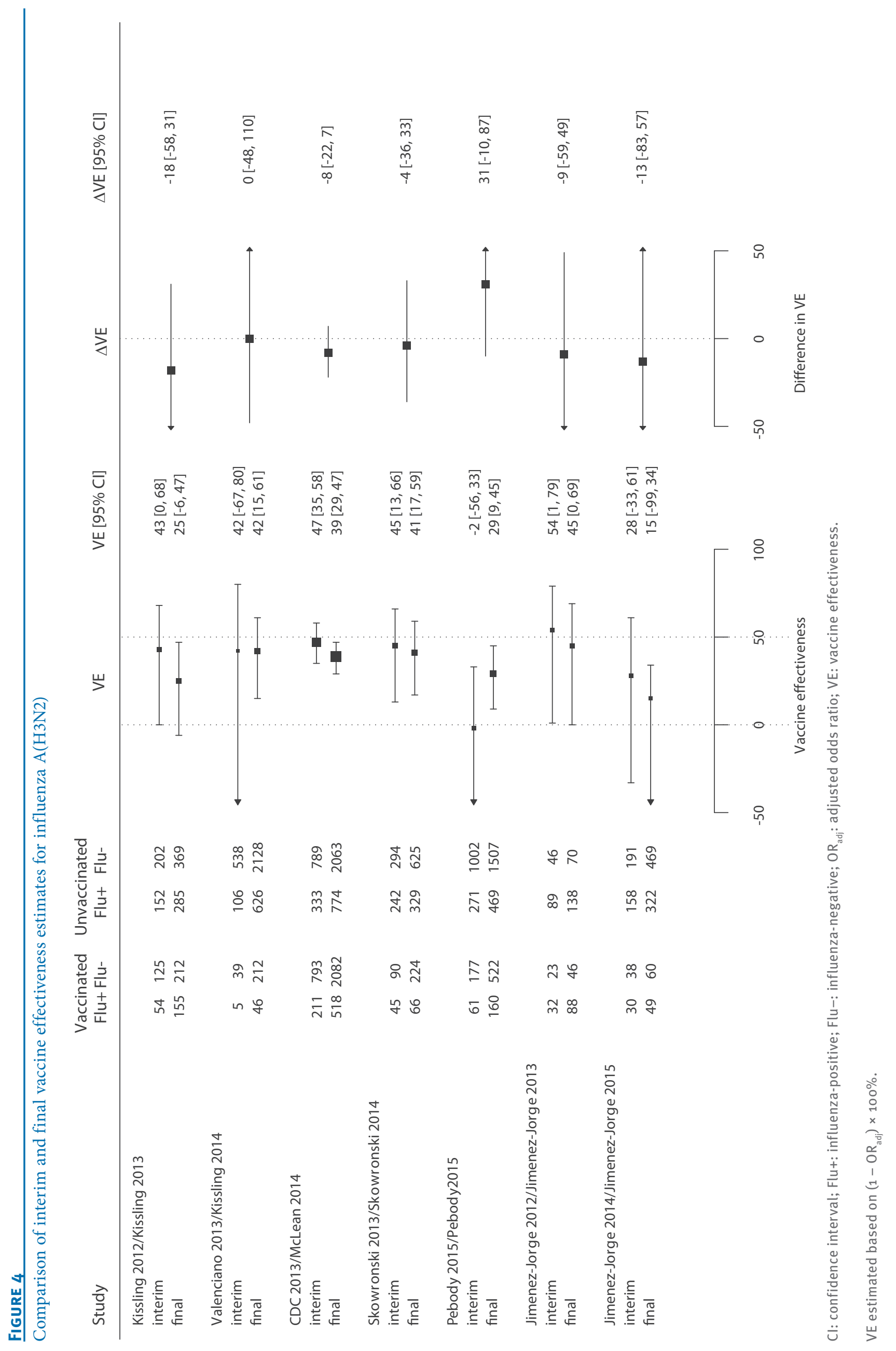




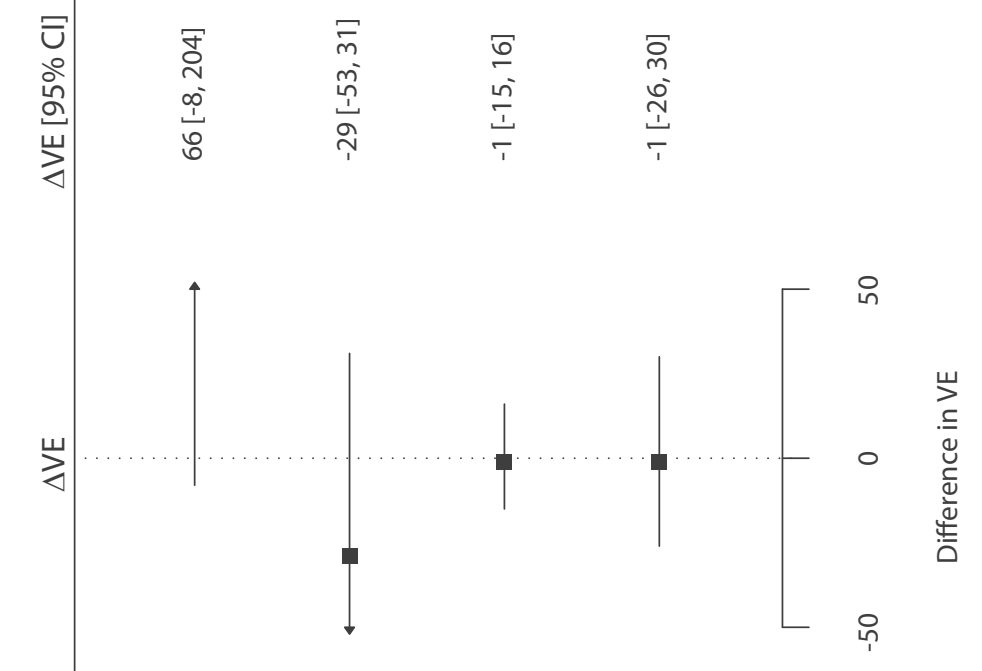

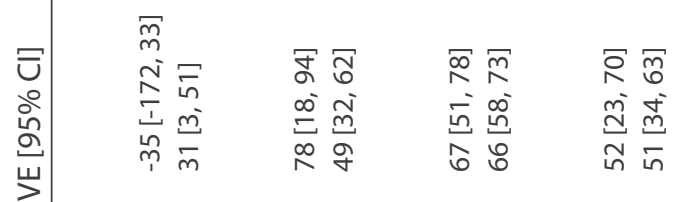

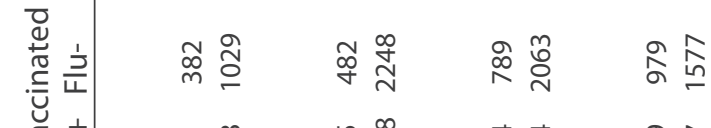

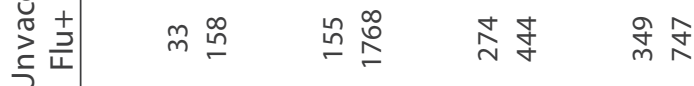

夈产 क

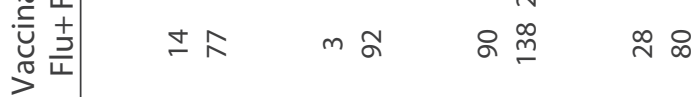

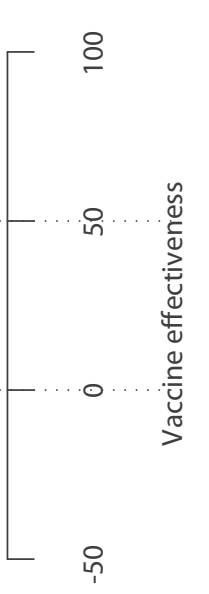

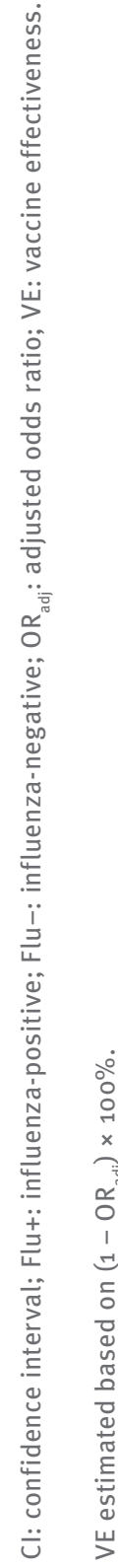


for sample size, proportion positive, proportion of vaccinated non-cases, number of weeks studied and number of covariates in the model. For other design features, the change in variable specification was used as a predictor; this included a change in specification of calendar time, vaccination definition, exclusion criteria related to time since onset, and statistical model. We also examined whether there was a change in the dominant strain during the season and whether the interim estimate was made before or after the peak. All analyses were performed using $\mathrm{R}$ version 3.1.3.

\section{Results}

Of the 43 interim studies reviewed (Figure 1), we located a corresponding final VE estimate for 17 [5-23,25-40].

The characteristics of the paired interim and final analyses are summarised in Table 1 . Studies were reported from North America, Europe and Australasia, with a total of 17 countries represented. The 2013/14 final published estimate for Spain was included as part of analyses comparing interim and final estimates over a number of seasons [23]. Two interim reports published for the 2012/13 northern hemisphere season in the United States (US) were published one month apart. The first interim estimate [41] was excluded from the comparison as the number of cases was substantially smaller than those used in the second interim estimate for the season [7]. Three interim studies reported agespecific estimates. No studies reported sex-specific estimates and only one interim study reported VE by risk group [16]. Eight northern hemisphere interim studies $[5,6,13-15,17,18,21]$ and one southern hemisphere study [10] were published before or during the World Health Organization's (WHO) vaccine strain selection meeting.

\section{Comparison of interim vs final vaccine effectiveness analyses}

Interim and final study pairs were reviewed to identify differences within and between pairs in the methods used to make estimates. A summary of these changes is shown in Table 2.

\section{Setting and source population}

In none of the study pairs were there changes to the study setting between interim and final estimates. One pair of studies from New Zealand reported estimates for both community and hospital settings $[20,37]$. The source population differed in the final analyses of three studies where data were pooled from multiple surveillance networks or sites $[31,33,36]$. Pooled final estimates commonly included data from additional surveillance sites which may not have had any cases at the time the interim estimate was made. For example, during the European 2011/12 season some countries were unable to provide data for the interim estimate [12]. In general, sample sizes in final analyses of VE increased compared with the interim analyses. One interim study reported a larger sample size $(n=285$ [19]) than the corresponding final estimate study $(n=262$ [26]), which was associated with the application of stricter criteria for the definition of the study period used and subsequent exclusion of many non-cases.

\section{Influenza-like illness definition}

The clinical case definition used to identify patients was generally termed influenza-like illness (ILI); however in the US studies, acute respiratory illness (ARI) was used as the clinical case definition. The list of symptoms included in each definition remained the same between the interim study and final study in all but one pair [27]. The interim analysis for the $2010 / 11$ season in Spain based the ILI definition on the International classification of primary care (ICPC) code for fever, whereas the final analysis provided a more specific definition for ILI. This did not appear to alter the point estimates for influenza $A\left(\mathrm{H}_{1} \mathrm{~N}_{1}\right)$ pdmo9 (interim VE: 58\%, 95\% confidence interval $(\mathrm{Cl}): 11-80$; final VE: $59 \%, 95 \% \mathrm{Cl}$ : 29-72) [5,27]. All studies included fever in the case definition for ILI, while only one study specified a temperature-based definition [13].

\section{Influenza case definition}

Cases of influenza were defined differently in two pairs of interim and final analyses. The case definition used in the interim analysis for the 2010/11 season in the United Kingdom (UK) [14] included individuals with ILI who were swab-positive for any influenza, regardless of type or subtype. The definition used in the final analysis [36] only included individuals who were swabpositive for influenza $A\left(\mathrm{H}_{1} \mathrm{~N}_{1}\right)$ pdmog or influenza $B$. Conversely, Kissling et al. [12] included only patients who were positive for influenza $\mathrm{A}\left(\mathrm{H}_{3} \mathrm{~N}_{2}\right)$ in their interim analysis, while the case definition for the final analysis included all patients who were swab-positive for any influenza [33]. However, the final analysis was later restricted to influenza $A\left(\mathrm{H}_{3} \mathrm{~N}_{2}\right)$ as this was the predominant circulating subtype during the season. Their end-of-season point estimate for influenza $A\left(\mathrm{H}_{3} \mathrm{~N}_{2}\right)$ decreased by 18 percentage points from the interim estimate (interim VE: $43 \%, 95 \% \mathrm{Cl}: 0-68$; final VE: $25 \%, 95 \% \mathrm{Cl}:-6$ to 47$)$.

\section{Exposure}

The classification of patients as vaccinated generally did not differ within study pairs. The definition for vaccination was not reported in the interim analysis for the Australian 2009 season [10]. In the final analysis [30], the vaccinated population was restricted to those presenting 14 days or more after vaccination.

\section{Study periods}

The criteria used to define the start of the study period for interim analyses varied among studies. Two studies started with the commencement of surveillance $[10,19]$, six started when there was evidence of circulation based on laboratory-confirmed cases $[5-8,16,20]$. Five studies used only the weeks with cases, a certain period after the vaccination campaign $[11,12,17,18,21,42]$, while four studies did not clearly define their study period [9,13-15]. 
TABLE 1

Studies reporting interim and corresponding final influenza vaccine effectiveness estimates $(n=34)$

\begin{tabular}{|c|c|c|c|c|c|c|c|}
\hline Reference & Study & $\begin{array}{c}\text { Interim/ } \\
\text { final }\end{array}$ & $\begin{array}{c}\text { Influenza } \\
\text { season }\end{array}$ & Country & Types of patients & Target groups & Vaccine \\
\hline [6] & CDC 2008 & Interim & $2007 / 08$ & United States & $\begin{array}{l}\text { Inpatients and } \\
\text { outpatients }\end{array}$ & All ages & TIV \\
\hline [22] & Belongia et al. 2011 & Final & $2007 / 08$ & United States & $\begin{array}{c}\text { Inpatients and } \\
\text { outpatients }\end{array}$ & All ages & TIV \\
\hline [10] & Kelly et al. 2009 & Interim & 2009 & Australia & Outpatients & All ages & TIV \\
\hline [30] & Kelly et al. 2011 & Final & 2009 & Australia & Outpatients & All ages & TIV \\
\hline [5] & Castilla et al. 2011 & Interim & $2010 / 11$ & Spain & $\begin{array}{c}\text { Inpatients and } \\
\text { outpatients }\end{array}$ & $\begin{array}{c}\text { Target group } \\
\text { for vaccination }\end{array}$ & TIV, MIV \\
\hline [27] & Castilla et al. 2012 & Final & $2010 / 11$ & Spain & $\begin{array}{c}\text { Inpatients and } \\
\text { outpatients }\end{array}$ & $\begin{array}{c}\text { Target group } \\
\text { for vaccination }\end{array}$ & TIV, MIV \\
\hline [42] & Kissling et al. 2011 & Interim & $2010 / 11$ & Europe & Outpatients & All ages & TIV \\
\hline [32] & Kissling et al. 2011 & Final & $2010 / 11$ & Europe & Outpatients & $\begin{array}{l}\text { Target group } \\
\text { for vaccination }\end{array}$ & $\begin{array}{c}\text { TIV, } \\
\text { adjuvanted } \\
\text { vaccine }\end{array}$ \\
\hline [14] & Pebody et al. 2011 & Interim & $2010 / 11$ & United Kingdom & Outpatients & All ages & TIV, MIV \\
\hline [36] & Pebody et al. 2013 & Final & $2010 / 11$ & United Kingdom & Outpatients & All ages & TIV, MIV \\
\hline [16] & Savulescu et al. 2011 & Interim & $2010 / 11$ & Spain & Outpatients & $\begin{array}{c}\text { Target group } \\
\text { for vaccination }\end{array}$ & TIV, AMIV \\
\hline [29] & Jimenez-Jorge et al. 2012 & Final & $2010 / 11$ & Spain & Outpatients & $\begin{array}{c}\text { Target group } \\
\text { for vaccination }\end{array}$ & TIV, MIV \\
\hline [12] & Kissling et al. 2012 & Interim & $2011 / 12$ & Europe & Outpatients & $\begin{array}{c}\text { Target group } \\
\text { for vaccination }\end{array}$ & TIV \\
\hline [33] & Kissling et al. 2013 & Final & $2011 / 12$ & Europe & Outpatients & $\begin{array}{c}\text { Target group } \\
\text { for vaccination }\end{array}$ & TIV \\
\hline [21] & Valenciano et al. 2013 & Interim & $2012 / 13$ & Europe & Outpatients & $\begin{array}{c}\text { Target group } \\
\text { for vaccination }\end{array}$ & TIV \\
\hline [31] & Kissling et al. 2014 & Final & $2012 / 13$ & Europe & Outpatients & $\begin{array}{c}\text { Target group } \\
\text { for vaccination }\end{array}$ & TIV \\
\hline [7] & CDC 2013 & Interim & $2012 / 13$ & United States & Outpatients & All ages & TIV \\
\hline [34] & McLean et al. 2014 & Final & $2012 / 13$ & United States & Outpatients & All ages & TIV \\
\hline [13] & McMenamin et al. 2013 & Interim & $2012 / 13$ & United Kingdom & Outpatients & $\begin{array}{c}\text { Target group } \\
\text { for vaccination }\end{array}$ & TIV \\
\hline [25] & Andrews et al. 2014 & Final & $2012 / 13$ & United Kingdom & Outpatients & All ages & TIV \\
\hline [19] & Sullivan et al. 2013 & Interim & 2013 & Australia & Outpatients & All ages & TIV \\
\hline [26] & Carville et al. 2015 & Final & 2013 & Australia & Outpatients & All ages & TIV \\
\hline [18] & Skowronski et al. 2013 & Interim & $2012 / 13$ & Canada & Outpatients & All ages & TIV \\
\hline [39] & Skowronski et al. 2014 & Final & $2012 / 13$ & Canada & Outpatients & All ages & TIV \\
\hline [43] & Skowronski et al. 2014 & Interim & $2013 / 14$ & Canada & Outpatients & All ages & TIV \\
\hline [38] & Skowronski et al. 2015 & Final & $2013 / 14$ & Canada & Outpatients & All ages & $\begin{array}{c}\text { TIV, LAIV, } \\
\text { adjuvanted } \\
\text { TIV }\end{array}$ \\
\hline [15] & Pebody et al. 2015 & Interim & $2014 / 15$ & United Kingdom & Outpatients & All ages & TIV \\
\hline [35] & Pebody et al. 2015 & Final & $2014 / 15$ & United Kingdom & Outpatients & All ages & TIV, LAIV \\
\hline [8] & Jimenez-Jorge et al. 2012 & Interim & $2011 / 12$ & Spain & Outpatients & $\begin{array}{c}\text { All ages, target } \\
\text { group for } \\
\text { vaccination } \\
\end{array}$ & TIV \\
\hline [28] & Jimenez-Jorge et al. 2013 & Final & $2011 / 12$ & Spain & Outpatients & $\begin{array}{c}\text { All ages, target } \\
\text { group for } \\
\text { vaccination } \\
\end{array}$ & TIV \\
\hline [9] & Jimenez-Jorge et al. 2014 & Interim & $2013 / 14$ & Spain & Outpatients & All ages & TIV \\
\hline [23] & Jimenez-Jorge et al. 2015 & Final & $2013 / 14$ & Spain & Outpatients & All ages & TIV \\
\hline [20] & Turner et al. 2014 & Interim & 2014 & New Zealand & $\begin{array}{l}\text { Inpatients and } \\
\text { outpatients }\end{array}$ & All ages & TIV \\
\hline [37] & Pierse et al. 2015 & Final & 2014 & New Zealand & $\begin{array}{l}\text { Inpatients and } \\
\text { outpatients }\end{array}$ & All ages & TIV \\
\hline
\end{tabular}

AMIV: adjuvanted monovalent influenza vaccine; CDC: Centers for Disease Control and Prevention; LAIV: live-attenuated influenza vaccine; MIV: monovalent influenza vaccine; TIV: trivalent influenza vaccine. 


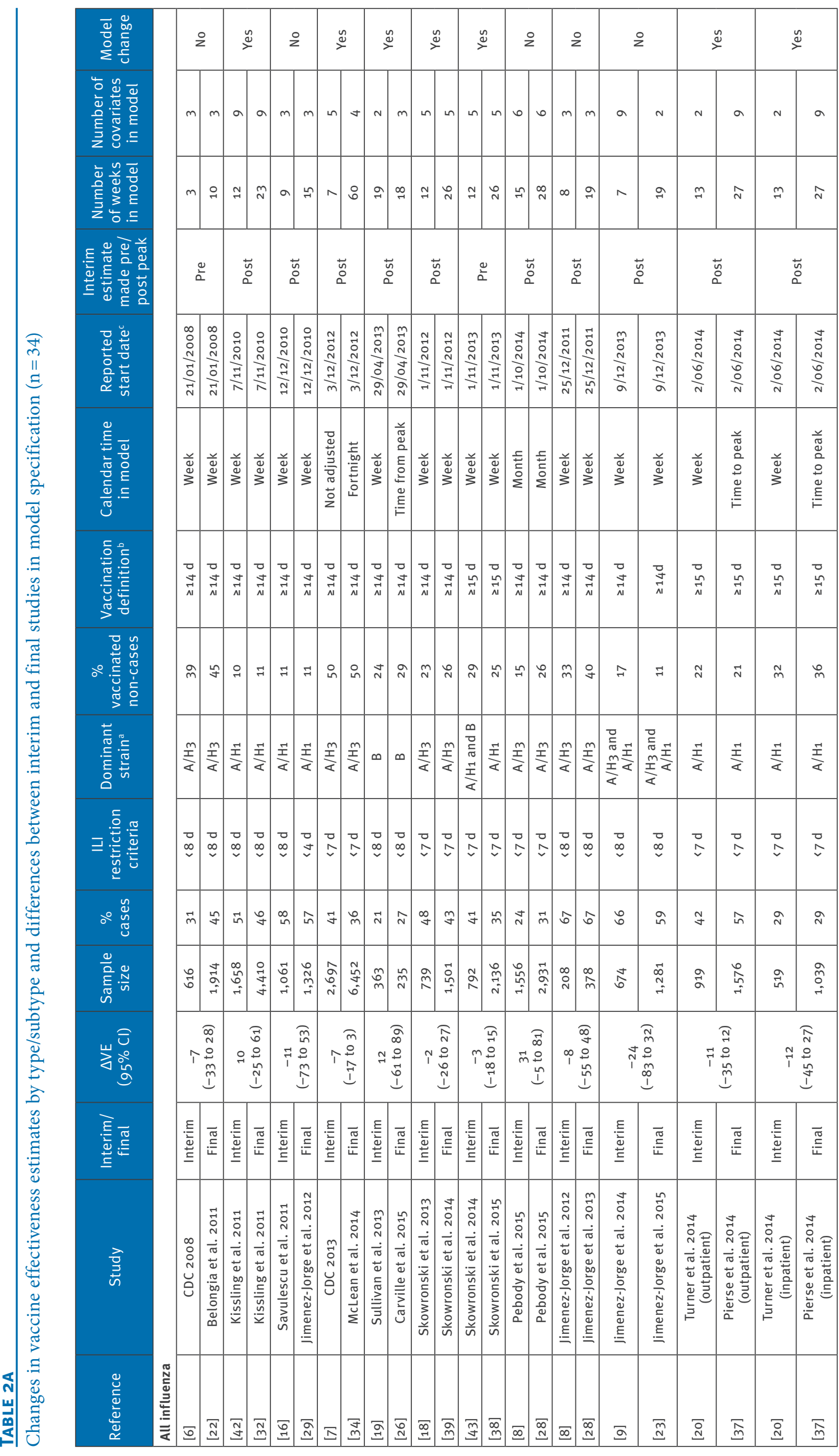

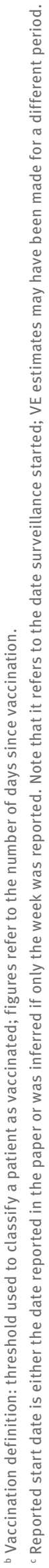




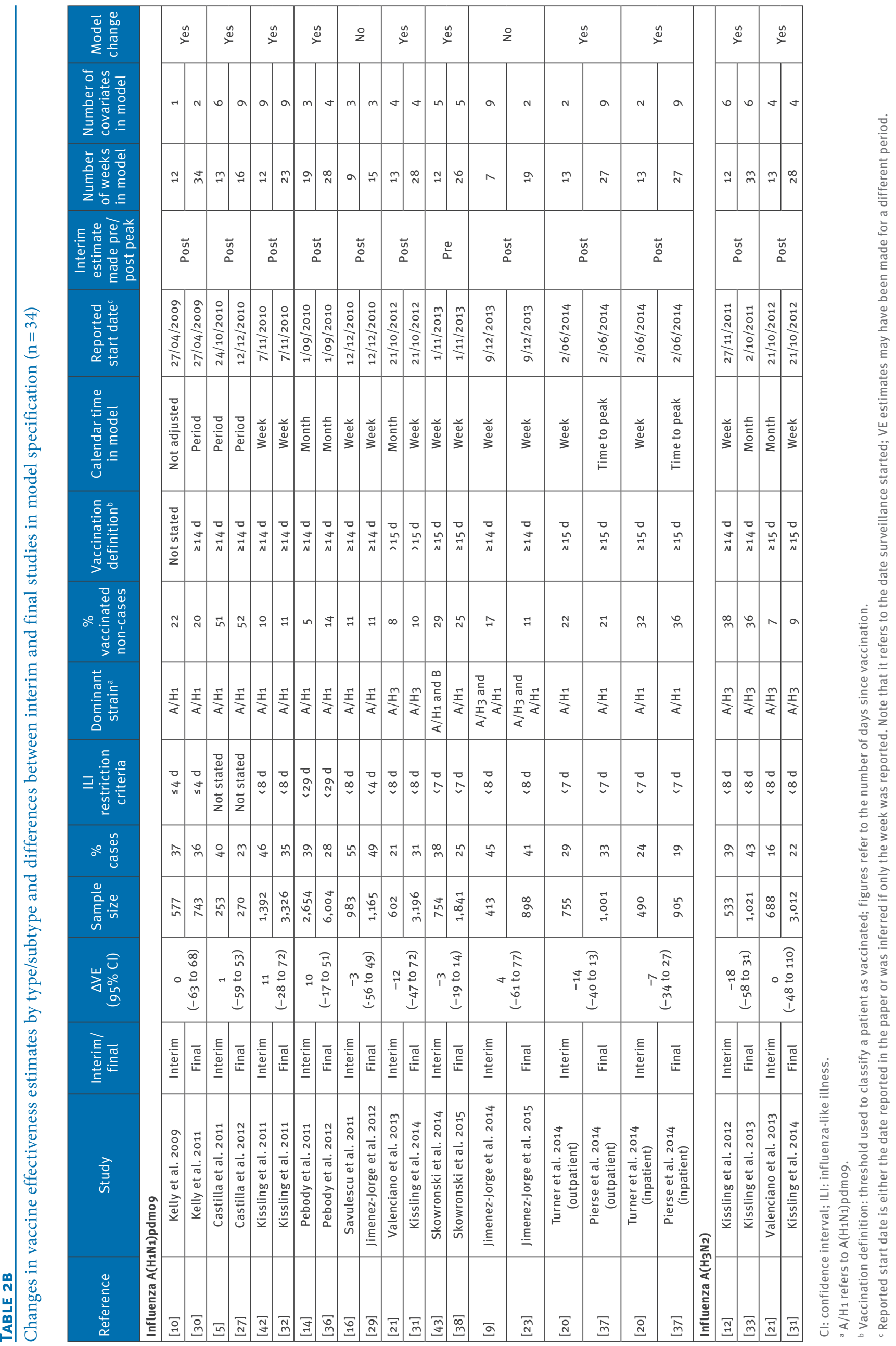




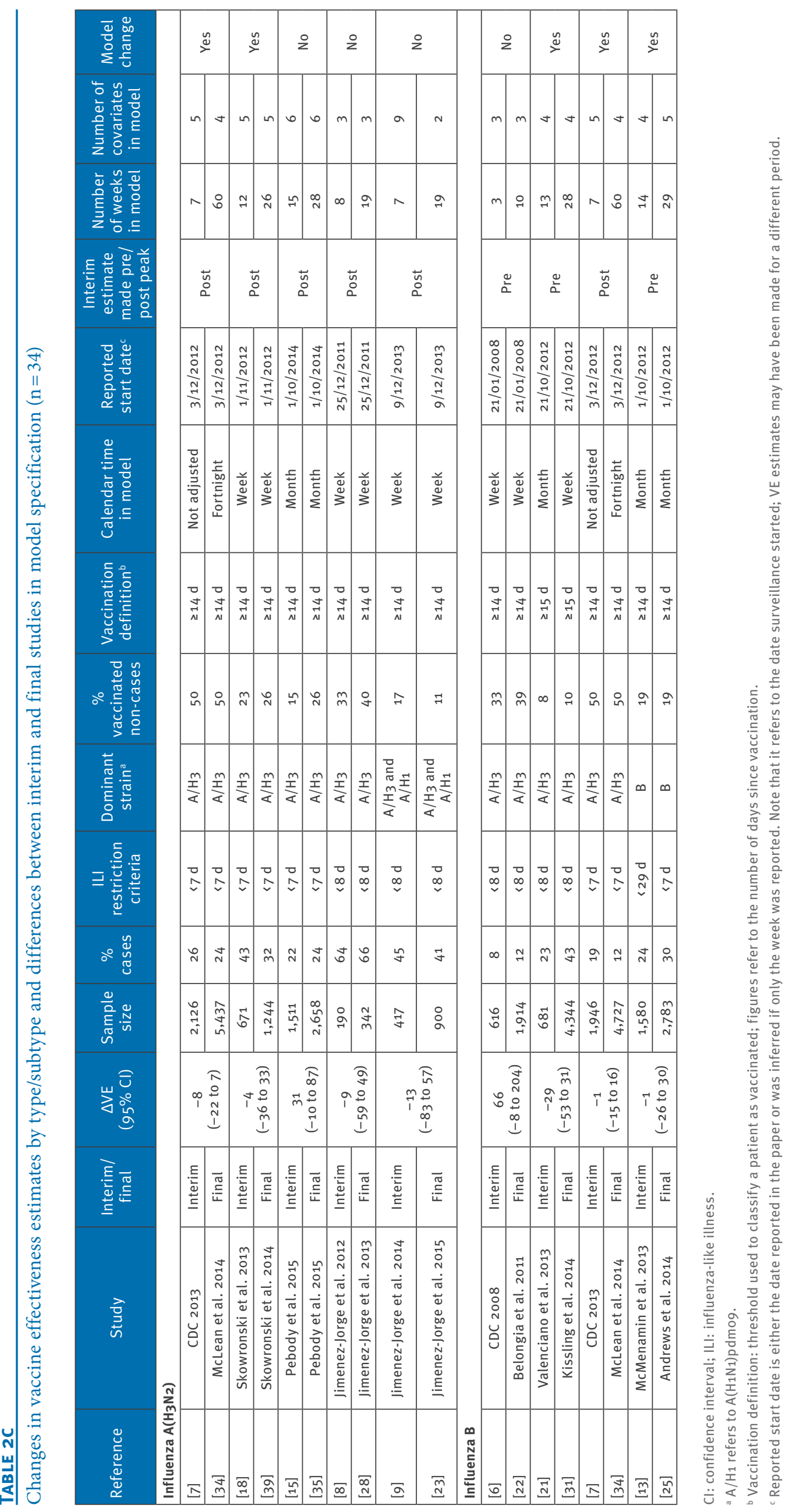


In general, the study period was defined in the same manner for final estimates, and the majority $(n=15)$ of studies commenced their study period on the same date for both interim and final analyses. In Spain in 2010/11, the interim analysis commenced in October, while the final analysis used data only from early December; the interim and final VE estimates made for influenza $A\left(\mathrm{H}_{1} \mathrm{~N}_{1}\right)$ pdmog against trivalent influenza vaccines (TIV) and monovalent influenza vaccines (MIV) were within 10 percentage points of each other $[5,27]$. Conversely, the study period reported for the European 2011/12 final analysis commenced earlier than the study period of the interim analysis, and larger variation between the estimates for influenza $A\left(\mathrm{H}_{3} \mathrm{~N}_{2}\right)$ was observed (VE: 43\%, 95\% Cl: 0-68\% [12] vs VE: $25 \%, 95 \% \mathrm{Cl}:-6$ to $47 \%$ [33], respectively). In Australia in 2013 , while the interim and final studies listed the same commencement date, the interim estimate was based on all available data for the surveillance period, while the final estimate was based on the weeks with cases and non-cases; thus the effective start date differed. The final estimate for all influenza (55\%, 95\% $\mathrm{Cl}:-11$ to 82 ) in that study pair [26] increased by 12 percentage points compared with the interim estimate (43\%, 95\% Cl: -30 to 75$)$ [19].

\section{Outcome}

Among interim studies, patients were restricted to those presenting within four [10], seven $[6,7,15,17-20]$, eight $[8,9,11,12,16,21]$ or 29 days $[13,14]$, while in one study, no such restrictions were mentioned [5]. These same restrictions applied in the final analyses in all but two studies. The interim estimate for the 2010/11 season in Spain restricted analyses to patients swabbed within eight days of symptom onset [16], whereas the final analyses was further restricted to within four days of symptom onset [8]. Similarly the $2012 / 13$ season in the UK applied a restriction of less than 29 days for their interim analysis [13] and altered the cut-off to less than seven days for the final analysis [25]. In both the Spanish and UK studies, final VE estimates were decreased compared with the interim estimates.

Variables included in the model to estimate vaccine effectiveness

Interim and final estimates for all influenza $(n=12$ studies) and for influenza $A\left(\mathrm{H}_{1} \mathrm{~N}_{1}\right)$ pdmog ( $\mathrm{n}=10$ studies) were most commonly reported, while seven studies reported estimates for influenza $A\left(\mathrm{H}_{3} \mathrm{~N}_{2}\right)$ and four studies reported estimates for influenza B. All studies used logistic regression to estimate VE. Compared with interim analyses (which used between one and nine variables), end-of-season VE models used between two and 10 variables. Differences in the variables included in regression models were noted in 12 of the paired studies.

All estimates were adjusted for age, specified as a categorical variable. The specification of age changed between interim and final analysis for six study pairs, either by the use of different categories $[22,26,27]$, re-specification as 10-year bands [32] or using cubic splines [31,34].

Calendar time was included in the model for 15 interim and corresponding final analyses. This variable was described in final analyses as a phase or period $[27,30,34]$, week of swabbing, enrolment or symptom onset $[22,23,28,29,31-33,38,39]$, month of sample collection or symptom onset $[25,35,36]$, or time relative to peak $[26,37]$. It was not included for two interim studies $[7,10]$ but subsequently included in the model to estimate end-of-season VE [30,34]. The definition of calendar time varied in three pairs of interim and final analyses. In the model used to estimate interim VE for the 2012/13 European season, month of symptom onset was included as the calendar time variable [21], while week of symptom onset was used in the final model instead [31]. In both the Australian 2013 and New Zealand 2014 studies, week of presentation was used in interim analyses $[19,20]$, while time relative to peak was used in the final analyses $[26,37]$.

Seven study pairs included some adjustment for the presence of chronic medical conditions in both interim and final analyses, while five included this adjustment only in the final analysis $[25-27,34,37]$.

Hospitalisation in the previous year, outpatient visits in the previous year and previous receipt of pneumococcal vaccine were included in the model to estimate end-of-season VE of one study, but were not included for adjustment in the interim analysis [5]. Another study adjusted for days from illness onset to enrolment, self-rated health and race/ethnicity [7] in the interim analysis, but did not adjust for these variables in their final analyses. Other variables included in both interim and final analyses included location or study site $[5,7,11,13-15,17,18,25,27,32,34-36,38,39]$, history of smoking $[8,11,28,32]$, receipt of previous influenza vaccine $[11,16,29,32]$ and children in the household $[5,27]$.

\section{Comparison of interim and final vaccine effectiveness estimates \\ Interim and final VE estimates by type and subtype are shown in Figure 2-5.}

In general, mid-season estimates were higher than end-of-season estimates. An absolute difference ofless than 10 percentage points between interim and final estimates was found for 18 of 33 reported pairs of estimates, including five of 12 pairs reporting VE against any influenza, six of 10 for influenza $A\left(\mathrm{H}_{1} \mathrm{~N}_{1}\right)$ pdmog, four of seven for influenza $A\left(\mathrm{H}_{3} \mathrm{~N}_{2}\right)$ and two of four for influenza B. The largest difference between interim and final estimates was observed in the 2008/og season in the US (interim VE: $-35 \%, 95 \% \mathrm{Cl}:-172$ to 33 [6]; final VE: $31 \%, 95 \% \mathrm{Cl}: 3-51$ [22]). In contrast, there were no changes to the point estimates for influenza $A\left(\mathrm{H}_{1} \mathrm{~N}_{1}\right)$ pdmog in the 2009 Australian season $[10,30]$ and for influenza $A\left(\mathrm{H}_{3} \mathrm{~N}_{2}\right)$ in the $2012 / 13$ European season 
TABLE 3

Summary of changes in study characteristics that influenced differences in vaccine effectiveness estimates

\begin{tabular}{|c|c|c|c|c|c|c|c|c|}
\hline \multirow{3}{*}{ Characteristic } & \multicolumn{4}{|c|}{ Linear model of $\triangle \mathrm{VE}$} & \multicolumn{4}{|c|}{ Logistic model of $\Delta V E>10 \%$} \\
\hline & \multicolumn{2}{|c|}{ Univariate } & \multicolumn{2}{|c|}{ Multivariable } & \multicolumn{2}{|c|}{ Univariate } & \multicolumn{2}{|c|}{ Multivariable } \\
\hline & $\beta$ (se) & $p^{a}$ & $\beta(\mathrm{se})$ & $\mathrm{p}^{\mathrm{a}}$ & $\begin{array}{c}\text { OR } \\
(95 \% \mathrm{Cl})\end{array}$ & $p^{b}$ & $\begin{array}{c}\text { OR } \\
(95 \% \mathrm{Cl})\end{array}$ & $p^{b}$ \\
\hline Intercept & NA & NA & $\begin{array}{c}-0.2046 \\
(3.42)\end{array}$ & 0.95 & NA & NA & $\begin{array}{c}4.55 \\
(0.9-63.24)\end{array}$ & NR \\
\hline Sample size & $\begin{array}{c}0.0003 \\
(0.0027) \\
\end{array}$ & 0.9 & NR & NR & $\begin{array}{c}1 \\
(1-1) \\
\end{array}$ & 0.7 & $\begin{array}{c}1.001 \\
(1.0001-1.002) \\
\end{array}$ & 0.07 \\
\hline Proportion of cases & $\begin{array}{l}-0.17 \\
(0.37) \\
\end{array}$ & 0.7 & NR & NR & $\begin{array}{c}1.09 \\
(1-1.21) \\
\end{array}$ & 0.1 & $\begin{array}{c}1.13 \\
(1-1.34) \\
\end{array}$ & 0.07 \\
\hline Proportion of non-cases vaccinated & $\begin{array}{l}1.85 \\
(0.61)\end{array}$ & 0.005 & $1.68(0.56)$ & 0.006 & $\begin{array}{c}1.07 \\
(0.92-1.27)\end{array}$ & 0.4 & NA & NR \\
\hline Number of additional weeks in final estimate & $\begin{array}{l}-0.19 \\
(0.24) \\
\end{array}$ & 0.4 & NR & NR & $\begin{array}{c}0.92 \\
(0.78-1)\end{array}$ & 0.2 & $\begin{array}{c}0.85 \\
\text { (0.67-0.95) } \\
\end{array}$ & 0.04 \\
\hline Number of covariates & $\begin{array}{l}-0.08 \\
(0.94)\end{array}$ & 0.9 & NR & NR & $\begin{array}{c}1.04 \\
(0.84-1.31) \\
\end{array}$ & 0.7 & NA & NR \\
\hline Change in calendar time specification (yes/no) & $\begin{array}{l}-12.03 \\
(5.95)\end{array}$ & 0.05 & $\begin{array}{l}-13.97 \\
(5.51)\end{array}$ & 0.02 & $\begin{array}{c}1.43 \\
(0.35- \\
5.98)\end{array}$ & 0.6 & NA & NR \\
\hline Change to vaccination definition (yes/no) & $\begin{array}{c}36.13 \\
(11.21)\end{array}$ & 0.4 & NR & NR & $\begin{array}{c}1.07 \\
(0.04- \\
28.62)\end{array}$ & 0.6 & NA & NR \\
\hline Change to restriction on duration of illness (yes/no) & $\begin{array}{l}-4.47 \\
(10.72)\end{array}$ & 0.7 & NR & NR & $\begin{array}{c}0.5 \\
(0.02- \\
5.77) \\
\end{array}$ & 0.6 & NA & NR \\
\hline Estimate made pre-peak (pre/post) & $\begin{array}{c}5.83 \\
(7.94) \\
\end{array}$ & 0.5 & $13.03(7.48)$ & 0.09 & $\begin{array}{c}0.46 \\
(0.06-2.8) \\
\end{array}$ & 0.4 & $\begin{array}{c}0.04 \\
(0-0.67) \\
\end{array}$ & 0.06 \\
\hline Change to predominant strain (yes/no) & $\begin{array}{c}-2.19 \\
(12.95) \\
\end{array}$ & 0.9 & NR & NR & Inest & Inest & NA & NR \\
\hline Any change to model specification (yes/no) & $\begin{array}{l}-9.18 \\
(6.54)\end{array}$ & 0.2 & NR & NR & $\begin{array}{c}0.69 \\
(0.16- \\
2.98)\end{array}$ & 0.6 & NA & NR \\
\hline
\end{tabular}

$\beta$ : regression coefficient; $\mathrm{Cl}$ : confidence interval; $\triangle \mathrm{VE}$ : difference in vaccine effectiveness estimates; inest: inestimable; NA: not applicable; NR: not retained; OR: odds ratio; se: standard error for the coefficient.

${ }^{a}$ In linear models, $p$ was measured by $t$-test.

b In logistic models, $\mathrm{p}$ was measures by chi-square test.

[21,31]. However, all interim and final estimates compared displayed overlapping confidence intervals.

Univariate linear regression models suggested that only the proportion of vaccinated non-cases had a significant effect on the value of $\triangle \mathrm{VE}$ (Table 3). The multivariate model identified that the proportion of vaccinated non-cases, change in how calendar time was specified and whether the interim estimate was made before the peak were the most influential variables; these were retained in the stepwise model. Using logistic regression, no design feature was identified as being statistically associated with a change in $\triangle V E$ of at least 10 percentage points in the univariate models. The stepwise model identified sample size, the proportion positive, the number of weeks studied, the proportion of vaccinated non-cases and whether the interim estimate was made before the peak as the most influential factors.

\section{Discussion}

We reviewed 17 pairs of published interim and final influenza VE studies that used the test-negative design to evaluate whether interim estimates can reliably predict final estimates. In general, interim estimates closely approximated final estimates, with 18 of 33 final estimates for all types and subtypes reported within 10 percentage points of their corresponding interim estimate. We attempted to explain discordance between pairs by examining their methodological differences and identified some inconsistencies between interim and final estimation. Within many of the study pairs, definitions for ILI, fever, study population, vaccination status, and the cut-off applied to the duration between patient presentation and symptom onset remained the same. The major differences were related to the change in study period and the concomitant changes in sample size, proportion vaccinated and proportion positive. In the two stepwise models we attempted, the variables identified as important predictors differed, with the exception of whether the interim estimate was 
made before or after the peak of the season. A previous study comparing interim and final estimates in Victoria, Australia, suggested that interim estimates may be most reliable when made after the peak of the influenza season, which was attributed to the gain in sample size when estimates are made later in the season. However, such a clear trend was not identified in a similar analysis performed in Spain [23].

Differences between interim and final estimates were most noticeable for estimates made against any influenza and influenza B. That concordance was better within subtypes possibly reflects how the summary estimate is influenced by individual specific type/subtype estimates as their prevalence changes throughout the season. Although we did not find a change in dominant strain to be an important predictor of $\Delta V E$, we were unable to capture the more subtle influence of changes in the proportionate mix of types/subtypes as the seasons progressed. We also noted that final estimates were generally lower than interim estimates, which raises questions about waning vaccine effectiveness as the season progresses.

The largest methodological differences within study pairs were in the specification of the statistical model. When we examined whether a change to the regression model was associated with a change in the VE estimate, we found no statistical difference. This is consistent with findings from Victoria, Australia, where it was noted that estimates varied only slightly when the model used for final estimates was modified [19], and raises the question of whether it is necessary to adjust for additional variables just because they are available. In studies of VE, we are trying to estimate a causal effect [24]. Thus, it could be argued that in principle, the model used for calculating VE should be decided a priori and should not change between interim and final estimation. We acknowledge that important information on known confounders may be incomplete when calculating interim estimates. In such cases, one must be mindful of statistical biases, such as biases associated with complete-case analysis, where missing data may not be missing at random, or sparse data, both of which can result in a loss of precision and inflated estimates. However, the use of identical methods provides an assurance that heterogeneity between interim and final estimates is not due to methodological differences and permits focus on other possible causes, such as the change in virus circulation and waning VE. As a minimum, reports should include in their sensitivity analyses a comparison of interim and final estimates using an identical analytical approach.

The results of our regression should be interpreted with caution. Firstly, the number of pairs available was probably insufficient to detect important associations, and certainly a multivariate model containing all predictors would have been overparameterised. With only 33 observations in the model, a change in value of any one predictor could substantially change the size and importance of the association estimated. We were also unable to explore any interactions and it is likely that the effect of any of predictors explored would vary across levels of other predictors. Secondly, although a study may have reported a certain study period, this did not necessarily correspond to the date range of the observations used in the VE estimation. This was noted in the 2013 studies in Australia, but could also happen as a consequence of covariate specification. For example, specification of week as a categorical variable can lead to perfect prediction [43] and loss of observations from weeks without both a case and a non-case. Truncation of the data by the regression programme will result in the loss of observations and reported sample sizes may therefore be misleading. Thus, it is possible that some of the predictors specified in our regression models were incorrectly calculated. Finally, we calculated $\Delta V E$ based on each study's point estimate only. Although $\Delta V E$ was calculated with a confidence interval, our regression models focussed on the median only. We did not exclude studies with large confidence intervals because their width is tied to sample size, which was one of the factors we were interested in exploring.

Interim estimates provide an early snapshot of the influenza vaccine's effectiveness during a season, but their validity and reliability needs to be assured. Endof-season estimates have advantages over interim estimates in terms of gains in sample size and the longer time available to undertake the analysis. However, they typically take more than six months to publish, which is well beyond their usefulness for policy. Interim estimates are also more useful than final estimates for decision making around vaccine composition. The WHO's Global Influenza Surveillance and Response System meets twice a year to generate a recommendation for the composition of the seasonal vaccine. Since February 2013, interim and final VE estimates generated from surveillance data have been presented at this meeting [44]. The utility of VE estimates in strain composition is limited to scenarios where the virological and serological data are inconclusive, there are suitable, alternative candidates vaccine viruses, and VE suggests poor performance of the current component. However, because of their timeliness, it is the interim, not the final, VE estimates that are informative in such a scenario.

Given the potential utility of interim VE estimates and the variability between methods used to estimate interim and final VE, it would be worthwhile implementing the use of a standard model for estimating interim VE. Such a model might include a minimum set of known confounders in the statistical model, use of standardised inclusion criteria, and minimum sample size and/or standard error requirements. In conducting this review, we identified inconsistencies in the way data are reported, particularly case and vaccination status, highlighting the need for a standardised reporting template. The similarities observed between 
interim and final estimates support the feasibility of generating and disseminating preliminary estimates of VE while virus circulation is ongoing.

\section{Acknowledgements}

Financial support: The WHO Collaborating Centre for Reference and Research on Influenza is funded by the Australian Government Department of Health. This work has received financial support from the Area of Excellence Scheme of the Hong Kong University Grants Committee (grant no. AoE/M-12/06) and the Harvard Center for Communicable Disease Dynamics from the National Institute of General Medical Sciences (grant no. U54 GMo88558). The funding bodies were not involved in the collection, analysis, and interpretation of data, the writing of the article, or the decision to submit it for publication.

\section{Conflict of interest}

$B J C$ has received research funding from MedImmune Inc. and Sanofi Pasteur for influenza vaccine efficacy and effectiveness studies, and has consulted for Crucell NV on pharmaceutical options for influenza control. The authors have no other relevant affiliations or financial involvement with any organisation or entity with a financial interest in or financial conflict with the subject matter or materials discussed in the manuscript apart from those disclosed.

\section{Authors' contributions}

VKYL undertook data collection and analysis, interpretation of the data and participated in manuscript development and editing. BJC conceptualised the study, undertook interpretation of the data and participated in manuscript development and editing. SF participated in data collection, data analysis and interpretation; SGS conceptualised the study, undertook data collection and analysis, interpretation of the data and participated in manuscript development and editing.

\section{References}

1. Sullivan SG, Tchetgen-Tchetgen E, Cowling BJ. Theoretical basis of the test-negative design for assessment of influenza vaccine effectiveness.Am J Epidemiol. 2016; (Forthcoming).

2. Foppa IM, Haber M, Ferdinands JM, Shay DK. The case test-negative design for studies of the effectiveness of influenza vaccine.Vaccine. 2013;31(30):3104-9. DOI: 10.1016/j. vaccine.2013.04.026 PMID: 23624093

3. Jackson ML, Nelson JC. The test-negative design for estimating influenza vaccine effectiveness.Vaccine. 2013;31(17):2165-8. DOI: 10.1016/j.vaccine.2013.02.053 PMID: 23499601

4. Orenstein EW, De Serres G, Haber MJ, Shay DK, Bridges CB, Gargiullo P, et al. Methodologic issues regarding the use of three observational study designs to assess influenza vaccine effectiveness. Int J Epidemiol. 2007;36(3):623-31. DOI: 10.1093/ije/dymo21 PMID: 17403908

5. Castilla J, Moran J, Martinez-Artola V, Reina G, Martinez-Baz I, Garcia Cenoz M, et al. Effectiveness of trivalent seasonal and monovalent influenza $A\left(\mathrm{H}_{1} \mathrm{~N}_{1}\right) 2009$ vaccines in population with major chronic conditions of Navarre, Spain: 2010/11 mid-season analysis. Euro Surveill. 2011;16(7):19799.PMID: 21345321

6. Centers for Disease Control and Prevention (CDC). Interim within-season estimate of the effectiveness of trivalent inactivated influenza vaccine--Marshfield, Wisconsin, 2007-08 influenza season.MMWR Morb Mortal Wkly Rep. 2008;57(15):393-8.PMID: 18418344

7. Centers for Disease Control and Prevention (CDC). Interim adjusted estimates of seasonal influenza vaccine effectiveness - United States, February 2013.MMWR Morb Mortal Wkly Rep. 2013;62(7):119-23.PMID: 23425960
8. Jiménez-Jorge S, de Mateo S, Pozo F, Casas I, Garcia Cenoz M, Castilla ], et al. Early estimates of the effectiveness of the 2011/12 influenza vaccine in the population targeted for vaccination in Spain, 25 December 2011 to 19 February 2012. Euro Surveill. 2012;17(12):20129.PMID: 22490308

9. Jiménez-Jorge S, Pozo F, de Mateo S, Delgado-Sanz C, Casas I, Garcia-Cenoz M, et al. Influenza vaccine effectiveness in Spain 2013/14: subtype-specific early estimates using the cycEVA study. Euro Surveill. 2014;19(9):20727. DOI: 10.2807/1560-7917.ES2014.19.9.20727 PMID: 24626206

10. Kelly H, Grant K. Interim analysis of pandemic influenza (H1N1) 2009 in Australia: surveillance trends, age of infection and effectiveness of seasonal vaccination.Euro Surveill. 2009;14(31):6419-26.PMID: 19660248

11. Kissling E, Valenciano M, I-MOVE case-control studies team. Early estimates of seasonal influenza vaccine effectiveness in Europe, 2010/11: I-MOVE, a multicentre case-control study.Euro Surveill. 2011;16(11):19818.PMID: 21435329

12. Kissling E, Valenciano M, I-MOVE Case-Control Studies Team. Early estimates of seasonal influenza vaccine effectiveness in Europe among target groups for vaccination: results from the I-MOVE multicentre case-control study, 2011/12.Euro Surveill. 2012;17(15):20146.PMID: 22516046

13. McMenamin J, Andrews N, Robertson C, Fleming D, Durnall $H$, von Wissmann B, et al. Effectiveness of seasonal 2012/13 vaccine in preventing laboratory-confirmed influenza infection in primary care in the United Kingdom: mid-season analysis 2012/13. Euro Surveill. 2013;18(5):20393.PMID: 23399421

14. Pebody R, Hardelid P, Fleming D, McMenamin J, Andrews N, Robertson C, et al. Effectiveness of seasonal 2010/11 and pandemic influenza $\mathrm{A}\left(\mathrm{H}_{1} \mathrm{~N}_{1}\right)_{2009}$ vaccines in preventing influenza infection in the United Kingdom: mid-season analysis 2010/11. Euro Surveill. 2011;16(6):19791.PMID: 21329644

15. Pebody RG, Warburton F, Ellis J, Andrews N, Thompson C, von Wissmann $B$, et al. Low effectiveness of seasonal influenza vaccine in preventing laboratory-confirmed influenza in primary care in the United Kingdom: 2014/15 mid-season results. Euro Surveill. 2015;20(5):21025. DOI: 10.2807/15607917.ES2015.20.5.21025 PMID: 25677050

16. Savulescu C, Jiménez-Jorge S, de Mateo S, Ledesma J, Pozo F, Casas I, et al. Effectiveness of the $2010 / 11$ seasonal trivalent influenza vaccine in Spain: preliminary results of a casecontrol study. Euro Surveill. 2011;16(11):19820.PMID: 21435330

17. Skowronski D, Chambers C, Sabaiduc S, De Serres G, Dickinson J, Winter A, et al. Interim estimates of 2013/14 vaccine effectiveness against influenza $A\left(\mathrm{H}_{1} \mathrm{~N}_{1}\right)$ pdmog from Canada s sentinel surveillance network, January 2014. Euro Surveill. 2014;19(5):20690. DOI: 10.2807/1560-7917. ES2014.19.5.20690 PMID: 24524234

18. Skowronski DM, Janjua NZ, De Serres G, Dickinson JA, Winter $\mathrm{AL}$, Mahmud SM, et al. Interim estimates of influenza vaccine effectiveness in 2012/13 from Canada's sentinel surveillance network, January 2013. Euro Surveill. 2013;18(5):20394.PMID: 23399422

19. Sullivan SG, Kelly H. Late season interim estimates of influenza vaccine effectiveness reliably predict end of season estimates in Victoria, Australia, 2007 to 2012. Euro Surveill. 2013;18(41):20605. DOI: 10.2807/1560-7917. ES2013.18.41.20605 PMID: 24135124

20. Turner N, Pierse N, Huang QS, Radke S, Bissielo A, Thompson $M G$, et al. Interim estimates of the effectiveness of seasonal trivalent inactivated influenza vaccine in preventing influenza hospitalisations and primary care visits in Auckland, New Zealand, in 2014. Euro Surveill. 2014;19(42):20934. DOI: 10.2807/1560-7917.ES2014.19.42.20934 PMID: 25358042

21. Valenciano M, Kissling E,, I-MOVE Case-Control Study Team. Early estimates of seasonal influenza vaccine effectiveness in Europe: results from the I-MOVE multicentre case-control study, 2012/13.Euro Surveill. 2013;18(7):20400.PMID: 23449183

22. Belongia EA, Kieke BA, Donahue JG, Coleman LA, Irving SA, Meece JK, et al. Influenza vaccine effectiveness in Wisconsin during the 2007-08 season: comparison of interim and final results. Vaccine. 2011;29(38):6558-63. DOI: 10.1016/j. vaccine.2011.07.002 PMID: 21767593

23. Jiménez-Jorge S, Pozo F, Larrauri A, cycEVA Study Team . Interim influenza vaccine effectiveness: A good proxy for final estimates in Spain in the last four seasons 2010-2014. Vaccine. 2015. DOI: 10.1016/j.vaccine.2015.03.051

24. Sullivan SG, Feng S, Cowling BJ. Potential of the test-negative design for measuring influenza vaccine effectiveness: a systematic review. Expert Rev Vaccines. 2014;13(12):1571-91. DOI: $10.1586 / 14760584.2014 .966695$ PMID: 25348015

25. Andrews N, McMenamin J, Durnall H, Ellis J, Lackenby A, Robertson C, et al. Effectiveness of trivalent seasonal influenza vaccine in preventing laboratory-confirmed influenza 
in primary care in the United Kingdom: 2012/13 end of season results. Euro Surveill. 2014;19(27):20851. DOI: 10.2807/15607917.ES2014.19.27.20851 PMID: 25033051

26. Carville KS, Grant KA, Sullivan SG, Fielding JE, Lane CR, Franklin $\mathrm{L}$, et al. Understanding influenza vaccine protection in the community: an assessment of the 2013 influenza season in Victoria, Australia. Vaccine. 2015;33(2):341-5. DOI: 10.1016/j. vaccine.2014.11.019 PMID: 25448093

27. Castilla J, Martínez-Artola V, Salcedo E, Martínez-Baz I, Cenoz MG, Guevara M, et al. Vaccine effectiveness in preventing influenza hospitalizations in Navarre, Spain, 2010-2011: cohort and case-control study. Vaccine. 2012;30(2):195-200. DOI: 10.1016/j.vaccine.2011.11.024 PMID: 22100636

28. Jiménez-Jorge S, de Mateo S, Delgado-Sanz C, Pozo F, Casas I, Garcia-Cenoz M, et al. Effectiveness of influenza vaccine against laboratory-confirmed influenza, in the late 2011-2012 season in Spain, among population targeted for vaccination. BMC Infect Dis. 2013;13(1):441. DOI: 10.1186/1471-2334-13-441 PMID: 24053661

29. Jiménez-Jorge S, Savulescu C, Pozo F, de Mateo S, Casas I, Ledesma J, et al. Effectiveness of the 2010-11 seasonal trivalent influenza vaccine in Spain: cycEVA study. Vaccine. 2012;30(24):3595-602. DOI: 10.1016/j.vaccine.2012.03.048 PMID: 22472792

30. Kelly HA, Grant KA, Fielding JE, Carville KS, Looker CO, Tran $\mathrm{T}$, et al. Pandemic influenza $\mathrm{H}_{1} \mathrm{~N}_{1} 2009$ infection in Victoria, Australia: no evidence for harm or benefit following receipt of seasonal influenza vaccine in 2009. Vaccine. 2011;29(37):641926. DOI: $10.1016 /$ j.vaccine.2011.03.055 PMID: 21473950

31. Kissling E, Valenciano M, Buchholz U, Larrauri A, Cohen JM, Nunes B, et al. Influenza vaccine effectiveness estimates in Europe in a season with three influenza type/subtypes circulating: the I-MOVE multicentre case-control study, influenza season 2012/13. Euro Surveill. 2014;19(6):20701. DOI: 10.2807/1560-7917.ES2014.19.6.20701 PMID: 24556348

32. Kissling E, Valenciano M, Cohen JM, Oroszi B, Barret A-S, Rizzo C, et al. I-MOVE multi-centre case control study 2010-11: Overall and stratified estimates of influenza vaccine effectiveness in Europe. PLoS One. 2011;6(11):e27622.

33. Kissling $E$, Valenciano $M$, Larrauri A, Oroszi B, Cohen JM, Nunes $B$, et al. Low and decreasing vaccine effectiveness against influenza $\mathrm{A}\left(\mathrm{H}_{3}\right)$ in $2011 / 12$ among vaccination target groups in Europe: results from the I-MOVE multicentre casecontrol study. Euro Surveill. 2013;18(5):20390.PMID: 23399425

34. McLean HQ, Thompson MG, Sundaram ME, Kieke BA, Gaglani $M$, Murthy $K$, et al. Influenza Vaccine Effectiveness in the United States During 2012-13: Variable Protection by Age and Virus Type. J Infect Dis. 2015;211(10):1529-40.

35. Pebody R, Warburton F, Andrews N, Ellis J, von Wissmann $B$, Robertson C, et al. Effectiveness of seasonal influenza vaccine in preventing laboratory-confirmed influenza in primary care in the United Kingdom: 2014/15 end of season results. Euro Surveill. 2015;20(36):30013. DOI: 10.2807/15607917.ES.2015.20.36.30013 PMID: 26535911

36. Pebody RG, Andrews N, Fleming DM, McMenamin J, Cottrell S, Smyth B, et al. Age-specific vaccine effectiveness of seasonal $2010 / 2011$ and pandemic influenza $A\left(\mathrm{H}_{1} \mathrm{~N}_{1}\right) 2009$ vaccines in preventing influenza in the United Kingdom. Epidemiol Infect. 2013;141(3):620-30. DOI: 10.1017/So950268812001148 PMID: 22691710

37. Pierse N, Kelly H, Thompson MG, Bissielo A, Radke S, Huang $\mathrm{QS}$, et al. Influenza vaccine effectiveness for hospital and community patients using control groups with and without non-influenza respiratory viruses detected, Auckland, New Zealand 2014. Vaccine. 2015.PMID:26685091

38. Skowronski DM, Chambers C, Sabaiduc S, De Serres G, Winter $A-L$, Dickinson JA, et al. Integrated sentinel surveillance linking genetic, antigenic and epidemiologic monitoring of influenza vaccine-virus relatedness and effectiveness during the 2013-2014 season. J Infect Dis. 2015;212(5):726-39. DOI: 10.1093/infdis/jiv177

39. Skowronski DM, Janjua NZ, De Serres G, Sabaiduc S, Eshaghi A, Dickinson JA, et al. Low 2012-13 influenza vaccine effectiveness associated with mutation in the eggadapted $\mathrm{H}_{3} \mathrm{~N}_{2}$ vaccine strain not antigenic drift in circulating viruses. PLoS One. 2014;9(3):e92153. DOI: 10.1371/journal. pone. 0092153 PMID: 24667168

40. Reed C, Kim IK, Singleton IA, Chaves SS, Flannery B, Finelli $\mathrm{L}$, et al. Estimated influenza illnesses and hospitalizations averted by vaccination--United States, 2013-14 influenza season. MMWR Morb Mortal Wkly Rep. 2014;63(49):1151-4. PMID: 25503917

41. Centers for Disease Control and Prevention (CDC). Early estimates of seasonal influenza vaccine effectiveness-United States, January 2013.MMWR Morb Mortal Wkly Rep. 2013;62(2):32-5.PMID: 23325354
42. Castilla J, Martinez-Baz I, Martinez-Artola V, Fernandez-Alonso M, Reina G, Guevara M, et al. Early estimates of influenza vaccine effectiveness in Navarre, Spain: 2012/13 mid-season analysis. Euro Surveill. 2013;18(7):2.PMID: 23449182

43. Heinze G, Schemper M. A solution to the problem of separation in logistic regression. Stat Med. 2002;21(16):2409-19. DOI: 10.1002/sim.1047 PMID: 12210625

44. Barr IG, Russell C, Besselaar TG, Cox NJ, Daniels RS, Donis R, et al. WHO recommendations for the viruses used in the 20132014 Northern Hemisphere influenza vaccine: Epidemiology, antigenic and genetic characteristics of influenza $A\left(\mathrm{H}_{1} \mathrm{~N}_{1}\right)$ pdmo9, $A\left(\mathrm{H}_{3} \mathrm{~N}_{2}\right)$ and $B$ influenza viruses collected from October 2012 to January 2013. Vaccine. 2014;32(37):4713-25. DOI: 10.1016/j.vaccine.2014.02.014 PMID: 24582632

\section{License and copyright}

This is an open-access article distributed under the terms of the Creative Commons Attribution (CC BY 4.0) Licence. You may share and adapt the material, but must give appropriate credit to the source, provide a link to the licence, and indicate if changes were made.

This article is copyright of the authors, 2016. 